\title{
Correlation between Grading Histopathology and Sentinel Lymph Node Metastasis in Early Breast Cancer in University of Sumatera Utara Hospital
}

\author{
Dedy Hermansyah $^{1 *}$ (D) Gracia Pricilia ${ }^{2}$, Arjumardi Azrah², Yolanda Rahayu ${ }^{2}$, Desiree A. Paramita ${ }^{2}$, Edwin S. Siregar $^{2}$ \\ ${ }^{1}$ Department of Surgery, Oncology Division, Faculty of Medicine, University of North Sumatera, Medan, Indonesia; ${ }^{2}$ Department \\ of Surgery, Faculty of Medicine, University of North Sumatera, Medan, Indonesia
}

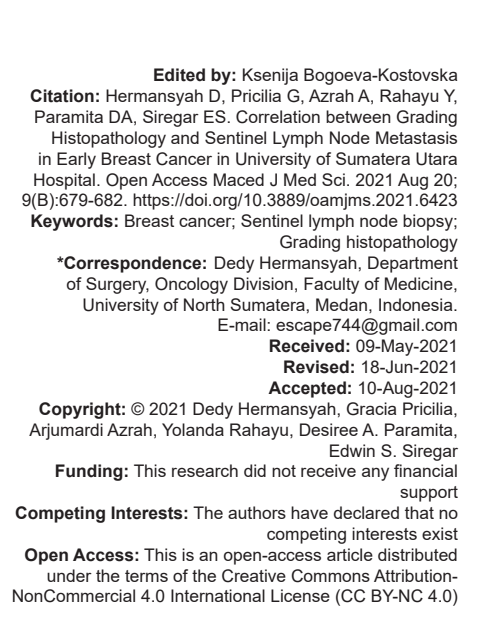

Introduction

Breast cancer is the most common cancer in women, with an incidence rate of $43.1 / 100,000$ people. In Indonesia, breast cancer is one of the most common types of cancer in Indonesia. The incidence of breast cancer in Indonesian women according to Globocan in 2012 was $40 / 100,000$ population. The incidence of breast cancer increased slightly from 2004 to 2013 and the mortality rate decreased by $38 \%$ from 1989 to 2014 [1], [2].

The early symptoms of breast cancer are often not recognized or felt clearly by patients; so many patients seek treatment in an advanced stage. Based on data from the medical records of Dharmais Cancer Hospital in 2010 , almost $85 \%$ of breast cancer patients came to the hospital in an advanced stage. This will affect the patient's prognosis and recovery rate. The American Joint Committee on Cancer (AJCC) staging system determines the most important prognostic factors for breast cancer, namely primary tumor size, regional lymph node status, distant metastases, and histological grade [3], [4].

The status of the axillary lymph nodes has been one of the strongest prognostic factors in women with early-stage breast cancer. Lymph node dissection (Axillary lymph node dissection [ALND]) has long been used as a method of identifying axillary lymph node metastases and is currently being replaced by another, more noninvasive methods, namely, sentinel lymph node biopsy (SLNB). The ALND method has often generated controversy due to increase morbidity in patients who did not have lymph node metastases. Eighty percent of women with axillary dissection experience complications such as decreased mobility, seroma formation, paresthesia or lymphedema, ipsilateral pain with axillary dissection, these complications can be difficult to manage, and significantly affect the patient's quality of life. There have been many advances in the treatment of breast cancer, and SLNB has been introduced as a minimally invasive procedure. With this SLNB procedure, patients with negative lymph node distribution do not need to have axillary lymph nodes being removed [5]. 
American Society of Clinical Oncology in 2014 recommends examination of sentinel lymph nodes in early-stage breast cancer with tumor size T1-T2 and clinically the axillary lymph nodes were not palpable enlargement [6]. SLNB can also be considered in patients with recurrent breast cancer after breastconserving therapy or mastectomy. SLNB is a minimally invasive technique that can confirm the presence of regional lymph node metastases in cancer [7].

There are several factors that predict the occurrence of lymph node metastasis, including tumor size, histological grading, lateral and retroareolar tumor location, presence of lymphovascular invasion, and HER-2 expression. Tumor grading is a description of a tumor based on the abnormality of tumor cells and tumor tissue seen under a microscope. This grading is determined based on the shape of tumor cells and the behavior of tumor cells compared to normal cells so that it can be seen how fast the cancer cells develop. Tumors with high histologic grade or poorly differentiated have a poor prognosis compared to low histologic grade or are well-differentiated without considering hormonal therapy or chemotherapy [8].

The Scarff Bloom Richardson grading system with the Nottingham modification has been used and recommended by the World Health Organization, the AJCC, the European Union (EU), and the Royal College of Pathologists (UKRC Path). The examination is based on the cytotocitural pattern and proliferation index of the tumor. It assesses glandular or tubular formation by tumor cells that reflect the cytoarchitecture pattern of the degree of differentiation of tumor cells against normal cells, nuclear pleomorphism that indicates tumor cell morphology. And the number of mitotic cells that shows a picture of tumor cell proliferation. Grading is associated with a life expectancy of 10 years, which Grade I (85\%), Grade II (60\%), and Grade III (45\%). Grade I shows the best prognosis, Grade II shows a moderate prognosis, whereas grade III shows the worst prognosis. Differences in histological grade to predict the presence of lymph node metastases can be useful in selecting patients with a greater risk of lymph node metastasis for more precise follow-up [8].

\section{Methods}

This research is an analytical study with a cross-sectional research design. The research is conducted at the Faculty Medicine of the University of North Sumatera teaching hospital. When the research is carried out after the ethics committee approves the proposal. The populations in this study are all breast cancer patients who came to the Faculty Medicine of the University of North Sumatera teaching hospital. The research samples are breast cancer patients who met the inclusion and exclusion criteria. Inclusion criteria include breast cancer patients and patients who had SLNB.

SLNB is generally performed during a mastectomy using 2-4 cc methylene blue dye 1\% injected periareolar and peritumoral. The histological grade examination was carried out based on a system that was modified by the NGS group by conducting a tumor histology assessment. The things that are checked include three morphological features, namely the degree of tubular or glandular formation, nuclear pleomorphism, and the number of mitosis. The tubular or glandular formation is examined throughout the tumor, as well as nuclear pleomorphism. Assessment of the amount of mitosis carried out in areas with the most active mitotic activity in the area of carcinoma. The examination is carried out using a value of $1-3$ for each point examined. The number of values $3-5$ indicates Grade 1 , values $6-7$ are grade 2, and values $8-9$ are grade 3 .

Data that have been collected processed and analyzed through statistics and presented in tabular form. Data were analyzed using the chi-square test. The data will be entered into a $2 \times 3$ table with histological grade independent variables, categorized as Grade 1, Grade 2, and Grade 3. The variables depend on positive or negative sentinel lymph node metastases. The result of data analysis is in the form of prevalence rate (PR).

\section{Results}

In this study, the data obtained were medical record data from June 2016 to August 2019. The number of samples that matched the inclusion and exclusion criteria was 51 people. The genders of all samples were women with the mean age of the patients were 49.39 years with a standard deviation of 8.511 years.

In Table 1, based on the characteristics of breast cancer, it was found that the largest breast tumor size was T2 in 44 patients $(86.3 \%)$, while the remaining T1 size was seven patients $(13.7 \%)$. Most types of breast cancer were invasive ductal carcinoma with 40 patients $(78.4 \%)$, then invasive no other specific type by 7 patients $(13.7 \%)$, then invasive lobular carcinoma and DCIS in 2 patients (3.9\%) each type.

Meanwhile, based on the results of the anatomical pathology examination, the highest grade was grade 3 , as many as 40 patients (78.4\%), followed by Grade 2, as many as 8 patients (15.7\%), and Grade 1, as many as 3 patients (5.9\%). Other characteristics, such as lymphovascular invasion (LVI) were detected positive in 25 patients $(49 \%)$, and negative in 26 patients (51\%). 
Immunohistochemical examination in 51 patients, obtained HER-2 (+) results in 12 patients $(23.5 \%)$. With at most 32 patients $(62.7 \%)$ having immunohistochemical results in the form of TNBC. About 7 patients $(13.7 \%)$ with immunohistochemical characteristics of ER/PR (+).

Table 1: Characteristics of research subjects

\begin{tabular}{lll}
\hline Age & $\mathrm{n}$ & $\%$ \\
\hline Age, (Mean \pm SD) & $49.39 \pm 8.511$ & \\
Gender & & 100 \\
Women & 51 & 0 \\
Male & 0 & 3.9 \\
Types of breast cancer & 2 & 78.4 \\
$\quad$ Ductal carcinoma in situ (DCIS) & 40 & 3.9 \\
Invasive ductal carcinoma & 2 & 13.7 \\
Invasive lobular carcinoma & 7 & \\
Invasive no other specific type & & 13.7 \\
Tumor size & 7 & 86.3 \\
T1 & 44 & 5.9 \\
T2 & & 15.7 \\
Grade & 3 & 78.4 \\
1 & 8 & 43 \\
2 & 40 & 57 \\
3 & & \\
LVI & 22 & 62.7 \\
Positive $(+)$ & 29 & 13.7 \\
Negative $(-)$ & & 23.5 \\
Immunohistochemistry & 32 & \\
ER/PR $(+)$ & 7 & \\
TNBC & 12 & \\
HER-2 $(+)$ & &
\end{tabular}

In Table 2 based on sentinel lymph node examination, there were 23 patients (45.1\%) with positive sentinel lymph node metastases and 28 patients (54.9\%) with lymph node sentinel without metastasis.

Table 2: Distribution of samples based on sentinel lymph gland metastases

\begin{tabular}{lll}
\hline KGB sentinel metastases & $\mathrm{n}$ & $\%$ \\
\hline Positive & 23 & 45.1 \\
Negative & 28 & 54.9 \\
\hline
\end{tabular}

The results of statistical tests, in Table 3, show that the $p=0.001$, it can be concluded that there is a significant relationship between grading and sentinel lymph node metastases. From the analysis, it was found that the proportion of patients with increasing grading was found to be more likely to not have sentinel lymph node metastases.

Table 3: Correlation between grading histopathology and sentinel lymph node metastases

\begin{tabular}{lllll}
\hline Grading & KGB sentinel & & P value * \\
\cline { 2 - 4 } & $(-)$ & $(+)$ & Total & \\
\hline I & $5(100 \%)$ & $0(0 \%)$ & $5(100 \%)$ & $0.001^{*}$ \\
II & $8(88.9 \%)$ & $1(11.1 \%)$ & $9(100 \%)$ & \\
III & $15(48.4 \%)$ & $22(51.6 \%)$ & $37(100 \%)$ & \\
Total & $28(54.9 \%)$ & $23(45.1 \%)$ & $51(100 \%)$ & \\
\hline${ }^{*}$ Fisher exact. & & & &
\end{tabular}

\section{Discussion}

Breast cancer, apart from being the most common cancer in women, is also a cancer with a high mortality rate in the world, and also in Indonesia. Based on GLOBOCAN 2018, the incidence rate was $24.2 \%$ of the total 8.6 million new cases, and the mortality rate was $15 \%$ of the 4.2 million reported deaths [9]. This mortality rate is strongly influenced by lymph node metastases, histological grade, tumor size, age, vascular invasion, and breast cancer subtypes [10].

The status of the axillary lymph nodes has been one of the strongest prognostic factors in women with early-stage breast cancer [11]. The lymph node metastasis correlation is even considered a more reliable prognostic and predictive factor than the breast cancer subtype [10].

In this study, the immunohistochemical status of ER/PR, TNBC, and HER-2 were found where the ER/ $P R$ rate was the highest compared to others. Meanwhile, in research conducted by Howland, Driver and Chao, it was found that HER-2 numbers were more dominant than others. While in a study conducted by $\mathrm{He}, \mathrm{Wu}$, Lin in 2015, the same characteristics were also found in this study, namely ER/PR, TNBC, and HER-2 [12], [13].

This study relates the grading of breast cancer with the presence or absence of sentinel lymph node metastases. Based on the analysis, it was found that there was a relationship between grading and sentinel lymph node metastases $(p=0.001)$. Based on the results of the analysis, the proportion of patients with increasing grading was found to have more sentinel lymph node metastases. The results of this study are consistent with research conducted by Zheng-Jun and Yue-Yu, who reported that there are many factors that are strongly associated with the number of lymph nodes that have metastases, including worse histological grade [14].

Another study conducted by Cserni et al. in 2007 correlating histopathological grading with SLN involvement showed that lower tumor grade was associated with reduced SLN involvement. In addition, multivariate analysis has clearly shown that only tumor grade (measured by a modified BloomRichardson histological score) and age are significantly associated with recurrence rate and that tumor size and tumor grade can predict significantly. significantly disease-free (DFS), regardless of ALND. According to these results, in the near future, the prognosis can be predicted more accurately with alternatives namely intrinsic biological tumor features, obtained by conventional histopathological characterization, immunohistochemical, or molecular biology, which can assess the potential for local and systemic tumor aggressiveness [14], [15].

When we considered the luminal breast cancer subtypes, the study of Jones et al. Found that only peritumoral LVI detection predicted the probability of SLN involvement; Neither histologic grade nor tumor size appears to influence metastatic risk. According to Cserni who studied the prognostic role of breast cancer. Subtypes in nodal involvement; they found a significant association between different breast cancer subtypes and age, tumor stage, histology, detection method and race, but no association with nodal involvement [15]. 


\section{Conclusion}

Based on this study, it was found that the most types of cancer were invasive ductal carcinoma. Histologically, the highest number of grade 3 breast cancer was found. The tumor size was obtained at T2 with 40 patients $(86.3 \%)$. From the histological grading examination and sentinel biopsy examination, it was found that there was relationship between histological grading and the occurrence of sentinel lymph node metastases $(p=0.001)$.

\section{Acknowledgment}

The authors would like to express the deepest gratitude to our colleagues and technicians from the University of North Sumatera who provided insight and expertise that assisted the research.

\section{References}

1. Ghoncheh M, Pournamdar Z, Salehiniya H. Incidence and mortality and epidemiology of breast cancer in the world. Asian Pac J Cancer Prev. 2016;17(3):43-6. https://doi.org/10.7314/ apjcp.2016.17.s3.43

PMid:27165206

2. Siegel RL, Miller KD, Jemal A. Cancer statistics. Am Cancer Soc. 2017;67(1):7-30. https://doi.org/10.3322/caac.21387 PMid:28055103

3. National Cancer Center Dharmais Hospital. Current Cancer Situation. Ministry of Health Cancer Bulletin. Indonesia: National Cancer Center Dharmais Hospital; 2013. p. 16.

4. American Joint Committee for Cancer. Breast Cancer Staging System. Part XI Breast. United States: American Joint Committee for Cancer; 2018. p. 621.

5. Soares EW, Nagai HM, Bredt LC, da Cunha AD, Andrade RJ, Soares GV. Morbidity after conventional dissection of axillary lymph nodes in breast cancer patients. World J Surg Oncol. 2014;12:1-8.
6. American Society of Clinical Oncology. Sentinel lymph node biopsy for patients with early-stage breast cancer: American society of clinical oncology clinical practice guideline update. J Clin Oncol. 2014;32(13):1365-83. https://doi.org/10.1200/ jco.2016.71.0947 PMid:24663048

7. Nieweg OE, Uren RF, Thompson JF. The history of sentine lymph node biopsy. Cancer J United States. 2015;21(1):3-6. https://doi.org/10.1097/ppo.0000000000000091 PMid:25611772

8. Stevens A, Lowe J, Scott I. Core Pathology. $3^{\text {rd }}$ ed. United Kingdom: Mosby Elsevier; 2009.

9. Brar P, Jain S, Singh I. Complications of axillary lymph node dissection in treatment of early breast cancer: A comparison of MRM and BCS. Indian J Surg Oncol. 2011;2(2):126-32. https:// doi.org/10.1007/s13193-011-0078-2 PMid:22693405

10. Bland KI, Copeland EM, Klimberg VS, Gradishar WJ, White J, Korourian S. The Breast: Comprehensive Management of Benign and Malignant Disease. $5^{\text {th }}$ ed. Philadelphia, PA: Elsevier; 2018.

11. Schröder L, Fricker R, Stein RG, Rink T, Fitz H, Blasius S, et al. Evaluation of sentinel lymph node biopsy prior to axillary lymph node dissection: The role of isolated tumor cells/micrometastases and multifocality/multicentricity-a retrospective study of 1214 breast cancer patients. Arch Gynecol Obstet. 2018;297(6):150915. https://doi.org/10.1007/s00404-018-4760-2 PMid:29594495

12. He ZY, Wu SG, Lin HX. Breast cancer subtype is associated with axillary lymph metastatic nodes. Medicine. 2015;94(48):e2213. https://doi.org/10.1097/md.0000000000002213

PMid:26632910

13. Howland NK, Driver TD, Sedrak MP, Wen X, Dong W, Hatch S. Lymph node involvement in immunohistochemistrybased molecular classifications of breast cancer. J Surg Res. 2013;185(2):697703. https://doi.org/10.1016/j.jss.2012.10.237 PMid:24095025

14. Giuliano AE, Connolly JL, Edge SB, Mittendorf EA, Rugo HS, Solin LJ, et al. Breast Cancer-major changes in the American joint committee on cancer eighth edition cancer staging manual. CA Cancer J Clin. 2017;67(4):290-303. https://doi.org/10.3322/ caac. 21393 PMid:28294295

15. Cserni G, Bianchi S, Vezzosi V, Arisio R, Bori R, Peterse JL, et al. Sentinel lymph node biopsy in staging small (Up To 15 $\mathrm{Mm}$ ) breast carcinomas. Results from a European multiinstitutional study. Pathol Oncol Res. 2007;13(1):5-14. https:// doi.org/10.1007/bf02893435

PMid:17387383 